\title{
Grupos sanguíneos en Costa Rica
}

\author{
por \\ C. A. Echandi * \\ (Recibido para su publicación el 15 de marzo de 1953)
}

Durante los años de 1946 a 1951 se realizaron, en el Laboratorio Bacteriológico del Hospital San Juan de Dios, 30.699 agrupaciones sanguíneas entre las cuales están comprendidas aquellas que se hace necesario practicar repetidamente a un mismo paciente cuando éste ha sido hospitalizado dos o más veces. Sin embargo, creemos que dado el alto número de exámenes en que hemos basado nisestros porcentajes, el error debido a este factor no afecta sustancialmente los datos aportados en este trabajo.

En la determinación del grupo sanguíneo se empleó la técnica de BETH VINCENT (1), de aglutinación en lámina, utilizando sueros aglutinantes $\mathrm{A}, \mathrm{B}$ y O preparados en el propio Laboratorio.

Los datos que obtuvimos revelan un porcentaje mayor de grupo $O$ sobre los otros grupos sanguíneos; siguiéndole en frecuencia los grupos $\mathrm{A}, \mathrm{B}$ y $\mathrm{AB}$ tespectivamente (Tabla I).

Comparando nuestros datos con los obtenidos por Picado y TREjos (2), encontramos pequeñas diferencias en los porcentajes correspondientes a los grupos A y O (Tabla II).

TABLA I

\begin{tabular}{c|c|c}
\hline Grupo & Número de personas & Por ciento \\
\hline A & 9561 & 31.14 \\
B & $4060 \quad 13.23$ \\
AB & 948 & 3.09 \\
O & 16.130 & 52.54 \\
\hline
\end{tabular}

En vista de que habían transcurrido más de 10 años entre el estudio por ellos realizado y el nuestro, levantamos la hipótesis de que esas diferencias observadas fueran indicio de un cruzamiento racial experimentado por nuestra población en los últimos años. Procedimos a aplicar el $\mathrm{X}^{2}$, según tabla de $\mathrm{R}$. A.

* División de Hematologia, Laboratorio Bacteriológico del Hospital San Juan de Dios. 
Fisher citada por Sinnott, Dunn y Dobzhansky (3) y encontramos que esas pequeñas diferencias no tienen valor significativo $y$ en modo alguno corroboran, por el momento, la hipótesis enuncia.da.

TABLA...II

\begin{tabular}{|c|c|c|c|c|}
\hline Datos de & \% B & $\%$ A & $\% \mathrm{AB}$ & $\% 0$ \\
\hline Picado y Trejos ... ... ... ... & 13 & 28 & 3 & 56 \\
\hline $\begin{array}{llllll}\text { Nuestros... } & \ldots & \ldots & \ldots & \ldots & \ldots\end{array}$ & 13.23 & 31.14 & 3.09 & 52.54 \\
\hline
\end{tabular}

Se realizaron además 1514 agtupaciones en niños que tenian de un día a un año de vida. Los resultados muestran cifras muy similares a los encontradas en personas de más edad, observándose una disminución de los grupos y $\mathrm{AB}$ y un aumento del grupo O. (Tabla III).

TABL.A III

\begin{tabular}{c|c|c|c|c|c}
\hline Edad & $\% \mathrm{~A}$ & $\% \mathrm{~B}$ & $\% \mathrm{AB}$ & $\% \mathrm{O}$ \\
\hline De más de un año ......... & 31.14 & 13.23 & 3.09 & 52.54 \\
De un día a un año ........ & 31.0 & 13.1 & 2.5 & 53.4 \\
\hline
\end{tabular}

Siendo que los aglutinógenos presentan una curva de aumento de asuerdo con la edad de la persona y que alcanzan su máximo a los tres años, pensamos en la posibilidad de encontrarnos en presencia de grupos incompletos que se comportaran por sus glóbulos como pertenecientes al grupo O. Sin embargo, la aplicación del $X^{2}$ indicó que las diferencias encontradas no tienen valor significativo.

\section{RESUMEN Y CONCIUSIONES}

Se obtienen los porcentajes para los cuatro grupos sanguíneos, sobre 30.699 agrupaciones hechas a pacientes del Hospital San Juan de Dios.

Se encuentra que no hay diferencias significativas entre los porcentajes encontrados en niños de menos de un año de vida y en personas de más edad.

\section{BIBLIOGRAFIA}

1. DUJARRIC DE LA RIVTRE R. \& N. KOSSOVTTCiI, 1936. Les groupes sanguins. 249 pp. J. B. Náilliere et Fils. Paris.

2. Picado, C. \& A. Trijos,

1942. Biologia bematológica elemental comparats. 408 pp. Imprenta Nacional. San José, Costa Rica.

3. Srnnotr, E. D., L. C. Dunn \& Th. Dobzhangs

1950. Principles of genetics. 4 edi., XIV +505 pp. Mc Graw.Hill Book $C^{q}, \mathrm{~N}$. X. 